\title{
SPION-Graphene Nanocomposites for Electrochemical Energy Storage and Conversion Devices
}

\author{
Vishwas N. Joshi ${ }^{1}$, Anuja-Ria Joshi ${ }^{2}$. \\ 1. Anvesha Labs Incorporated, Setauket, NY, USA. \\ 2. Stony Brook University, Stony Brook, NY, USA.
}

Superparamagnetic iron oxide nanoparticle (SPION) nanostructures by themselves suffer from aggregation after reaction, poor capacity retention and low electronic conductivity [1]. Graphene, a 2D material wherein carbon atoms are in a hexagonal arrangement, has high surface area, high conductivity, excellent chemical and thermodynamic stability, unique light-weight characteristic and superior optical, thermal and mechanical properties [2]. Aggregation or restacking of graphene reduces specific surface area of electrodes and negatively affects electrode and device performance [2], whereas, SPIONgraphene nanocomposites (SPION-GNCs) minimize graphene aggregation and restacking and exhibit synergistic effects, and enhanced electrode and device performance [3].

Herein, we report preparation of SPION-GNCs by thermal treatment of SPIONs stabilized with methoxy-polyethylene glycol-carboxylic acids (mPEG-COOHs). mPEG-OHs (0.5-5 kDa) were oxidized to mPEG-COOHs [4] by following methods: i) sulfuric acid/chromium trioxide; ii) Copper (I) Chloride and 2,2,6,6-tetramethyl-1-piperidinyloxyl (TEMPO) under ambient/aerobic conditions; iii) aerobic oxidation with TEMPO and ceric ammonium nitrate; and iv) TEMPO and oxygen $\left(\mathrm{O}_{2}\right)$ under very high pressure at 20 to $40{ }^{\circ} \mathrm{C}$. TEMPO/O 2 at $>10$ atmospheres and room temperature produced clean mPEGCOOHs after 48 to $72 \mathrm{~h}$ without any detectable degradation products. TEMPO can be removed by washing the final product with saturated sodium thiosulfate solution acidified with hydrochloric acid. This method is suitable for large-scale production of mPEG-COOHs; however, an expensive highpressure reactor and appropriate engineering controls for safe $\mathrm{O}_{2}$ venting are required.

mPEG-COOH stabilized SPIONs were prepared by heating a mixture of Fe(III)-organometallic complex and mPEG-COOH in 2-pyrrolidone at $200-300{ }^{\circ} \mathrm{C}$ for 1.5 to $5 \mathrm{~h}$. The average size of the SPIONs can be manipulated (4 to $10 \mathrm{~nm}$ diameter) by adjusting $\mathrm{Fe}(\mathrm{III})$-complex-to-mPEG-COOH molar ratio and mPEG-COOH molecular weight.

SPION-GNCs were prepared by heating mPEG-COOH stabilized SPIONs at $125^{\circ} \mathrm{C}$ to $175^{\circ} \mathrm{C}$ for $2 \mathrm{~h}-$ 72h. Fig. 1 shows STEM and HRTEM of SPION-GNC that was prepared by heating mPEG-2k-COOH stabilized SPIONs at $135^{\circ} \mathrm{C}$ for $4 \mathrm{~h}$ \{ The mPEG-2k-COOH stabilized SPIONs were prepared heating a mixture of mPEG-2k-COOH and Fe(III)- organometallic complex (1:4 molar ratio) at $200{ }^{\circ} \mathrm{C}$ for $0.5 \mathrm{~h}$, followed by heating at $300{ }^{\circ} \mathrm{C}$ for $4 \mathrm{~h}$; all the results presented here are for this SPION-GNC sample . The SPION particle sizes range from 2 to $20 \mathrm{~nm}$ with an average size of $\sim 10 \mathrm{~nm}$ (Fig. 1A) and have a crystalline structure (Fig 1. B-D). HRTEM also shows the presence of graphene nanoparticles (GNPs) as judged from contrast and lattice parameters (Fig 1B). The STEM-EDS shows that the SPIONs are dispersed in graphene; the copper signal in EDS is from the grid and silicon signal is likely from glassware used for synthesis (data not shown).

The saturation magnetization $\left(\mathrm{Ms}=1.99 \times 10^{-4} \mathrm{emu}\right)$, remanent magnetization $\left(\mathrm{Mr}=1.39 \times 10^{-5} \mathrm{emu}\right)$, and squareness $(\mathrm{Ms} / \mathrm{Mr}=0.07)$ values $(295.15 \mathrm{~K}$; thin film) indicate that superparamagnetism of the SPIONs is retained following SPION-GNC synthesis (Fig. 2A). XPS data further confirms that the 
hybrid nature of SPION-graphene composite (Fig. 2B). SEM/EDX analysis shows higher composition of carbon than iron suggesting that the SPIONs are dispersed in graphene matrix (data not shown). The current-voltage curves for SPION-GNC are not linear suggesting their non-conducting/semiconducting nature at room temperature, while thermogravimetric analysis indicates $\sim 37.4 \%$ graphene/organic contents. Further, the specific capacity of SPION-GNC drops from $\sim 935 \mathrm{~mA} \mathrm{~h} \mathrm{~g}^{-1}$ for the first cycle to $\sim 320 \mathrm{~mA} \mathrm{~h} \mathrm{~g}^{-1}$ for the $50^{\text {th }}$ cycle at $100 \mathrm{~mA} \mathrm{~g}^{-1}$ charge/discharge rate (data not shown).

Efforts are underway to produce SPION-GNCs with improved performance for electrochemical energy storage and conversion devices, e.g., electrodes for rechargeable lithium ion batteries and supercapacitors for portable electronic devices and hybrid electric vehicles.

\section{References:}

[1] G. Huang, et al, ACS Appl. Mater. Interfaces, 6 (2014) 7236.

[2] D. Chen, et al, Chem. Rev., 112 (2012) 6027.

[3] L. Li, et al, Carbon, 67 (2014) 500.

[4] M. Hudlicky, "Oxidations in Organic Chemistry” (ACS, Washington DC).
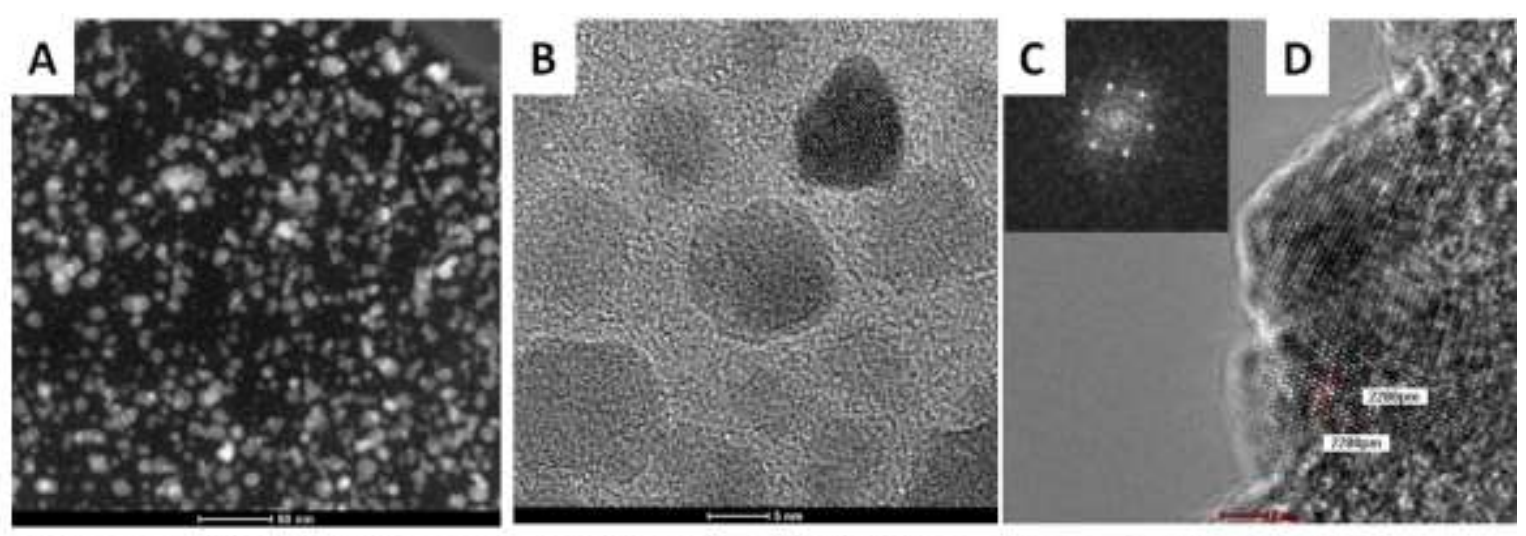

Figure 1. STEM (A) and HRTEM (B) of SPION-graphene hybrid particles. The diffractogram (C) and lattice parameters (D) suggest crystalline structure.
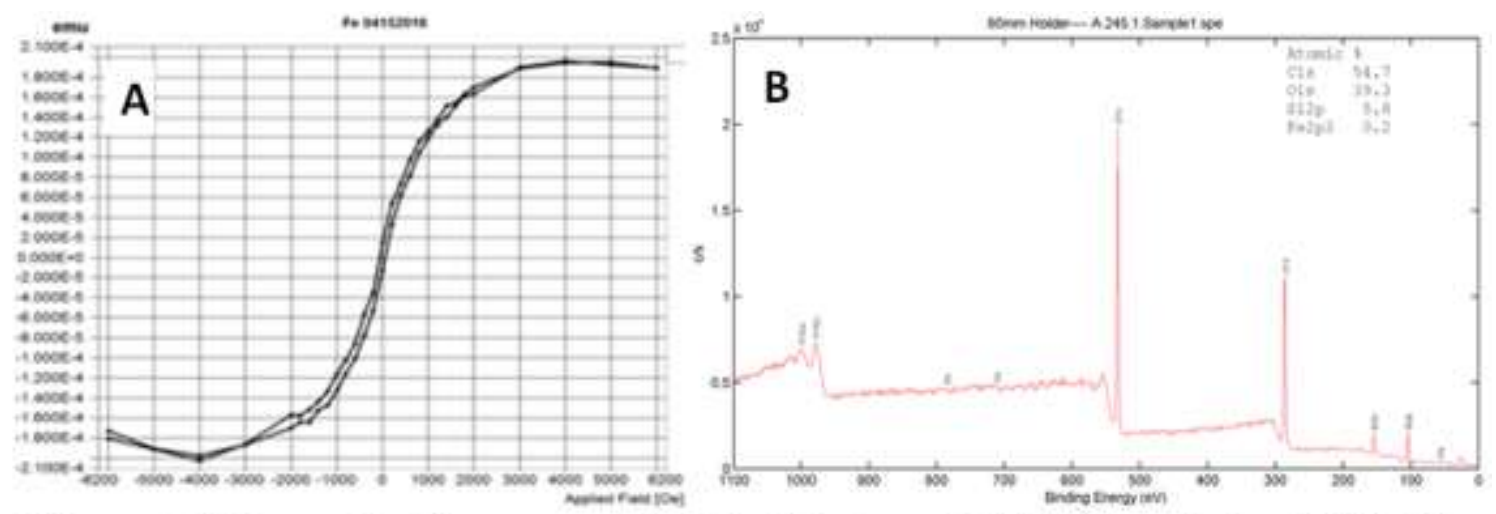

Figure 2. Magnatization curve (A; thin film) and XPS (B; dried) of SPIONgraphene composite particles prepared from mPEG-2k-stabilized SPIONs. 